\title{
O Estado plurinacional da Bolívia e do Equador: matrizes para uma releitura do direito internacional moderno*
}

\author{
The Plurinational States of Bolivia and Ecuador: \\ Foundations for a rereading \\ of Modern International Law
}

\author{
Henrique Weil Afonso** \\ José Luiz Quadros de Magalhães***
}

SUMARIO: I. Introdução. II. O direito internacional moderno. III. 1492:

as origens do direito internacional moderno. IV. O Estado plurinacional boliviano e equatoriano. V. Considerações finais. VI. Bibliografia.

* Artículo recibido el 27 de mayo de 2011 y aprobado para publicación el 28 de septiembre de 2011.

** Bacharel em Direito (UFJF); mestre e doutorando em Direito (PUC-MG); professor do Centro Universitário de Sete Lagoas (UNIFEMM).

*** Bacharel, Mestre e Doutor em Direito (UFMG); professor dos cursos de graduação, mestrado e doutorado da PUC-MG, da UFMG, da Faculdade do Sul de Minas e da Universidade de Buenos Aires. 
RESUMEN: Las nuevas Constituciones de Bolivia (2008) y Ecuador (2008) pueden representar una ruptura con el modelo de Estado-nación moderno con importantes implicaciones para el derecho internacional. La aparición de nuevas formas de organización en estas sociedades interculturales impregna las bases del moderno Estado-nación europeo al proponer la reformulación y la búsqueda de alternativas a las barreras culturales y epistemológicas propias de la modernidad. Este documento analiza los orígenes del moderno derecho internacional y la consolidación de los órganos del Estado para llevar a cabo, finalmente, una discusión de las Constituciones plurinacionales, sus instrumentos para hacer frente a la diversidad y la propuesta constitucional más amplia. Concluye con la reflexión de que la plurinacionalidad potencialmente puede ofrecer nuevas lecturas de la ley internacional.

Palabras clave: Estado plurinacional, la modernidad, el multiculturalismo.

ABSTRACT: The new Constitutions of Bolivia (2008) and Ecuador (2008) may represent a break with the model of modern nation-state with important implications for international law. The emergence of new forms of organization in these intercultural societies permeates the foundations of modern European nation-state when proposing the reformulation and the exploration for alternatives to cultural and epistemological barriers typical of modernity. This paper examines the origins of modern international law and the consolidation of state bodies to carry out, finally, a discussion of multinational Constitutions, their instruments to address diversity and the broader constitutional proposal. It concludes with the reflection that plurinationality can potentially offer new interpretations of international law.

Keywords: multinational State, modernity, multiculturalism.

RÉSUMÉ : Les nouvelles Constitutions de la Bolivie (2008) et l'Equateur (2008) peut représenter une rupture avec le modèle d'État-nation moderne avec des implications importantes pour le droit international. L'apparition de nouvelles formes d'organisation dans ces sociétés interculturelles imprègne les bases d'État-nation moderne européenne puisqu'il propose la reformulation et la recherche d'alternatives aux barrières culturelles et épistémologiques de la modernité. Ce document examine les origines du droit international moderne et la consolidation des organes de l'État pour mener à bien, finalement, une discussion des Constitutions plurinationales, leurs instruments pour répondre à la diversité et la proposition constitutionnelle plus grande. Il finit avec la réflexion sur qui la plurinationalité potentiellement peut offrir des interprétations nouvelles du droit international.

Mots-clés: Etat plurinational, la modernité, le multiculturalisme. 


\section{INTRODUÇÃO}

As novas constituições da Bolívia e do Equador do ano de 2008 são uma grande novidade para o Direito, pois têm o potencial de significar uma ruptura com o modelo estatal moderno. Da uniformização e unificação — para não falar na intolerância religiosa e cultural_—, elementos estes que forjam a base valorativa do Estado-nação advindo da tradição européia, o Estado Plurinacional pretende fornecer novos paradigmas não somente em termos de organização social, mas também atender às demandas dos povos e nações historicamente marginalizados no processo "civilizatório" americano, africano e asiático.

O delineamento das características elementares do Direito Internacional Público moderno é apresentado inicialmente, tomando-se o substrato westphaliano como ponto de partida. A formação do Estadonação na Europa, com a posterior propagação ao redor do globo, complementam a primeira seção, ocasião em que são identificadas as bases uniformizadoras do projeto de Estado moderno, e suas implicações para a disciplina internacionalista.

A segunda parte propõe uma abordagem crítica ao Direito Internacional e à instituição estatal. O conteúdo mítico de modernidade é então apresentado, fundamentado nas teorias de Enrique Dussel e Tzvetan Todorov, a fim de investigar as origens modernas do Direito das Gentes. As alternativas epistemológicas ao universalismo europeu transcorrem um processo de desconsideração e encobrimento, essenciais, em seu turno, à gênese do pensamento moderno e da formação da identidade europeia.

A apresentação dos processos históricos que desencadearam a formação das novas Constituições boliviana e equatoriana, assim como a discussão acerca do tipo de inovação que lhes é possível, compõem o conteúdo da última seção. Por se tratar de evento demasiado recente, há de se verificar um propósito descritivo e, ao final, sugestivo e reflexivo, por almejar a releitura de dogmas seculares da doutrina internacionalista, profundamente enraizada nos padrões valorativos do Estado moderno e do tipo de relação para o outro -o diferente--daí resultante. 


\section{O DIREITO INTERNACIONAL MODERNO}

O marco temporal tradicionalmente apontado como o alicerce do Direito Internacional moderno corresponde aos Tratados de Westphalia (1648), que puseram fim à Guerra dos Trinta Anos. Uma "ordem criada por estados, para estados" , a Paz de Westphalia fracionou impérios, consolidou fronteiras e revogou o direito anterior.

No mesmo período, Hugo Grotius admitiu a coexistência de um Direito Natural e de um direito positivo. Identificou o fundamento do jusnaturalismo não na vontade divina, mas na natureza social do homem, para posteriormente situar o Direito Natural acima dos indivíduos e do Estado. Desenvolveu a Teoria da Guerra Justa, excluindo a razão utilitária, e pregando que a guerra, quando justa, deve ser travada com moderação. $^{2}$

No entender de Malcolm N. Shaw, foi a evolução do conceito de sociedade internacional composta por Estados separados, soberanos e em constante competição, o marco da compreensão atual do Direito Internacional. ${ }^{3}$ Teóricos como Jean Bodin e Emer de Vattel contribuíram substancialmente para a consolidação da doutrina da soberania e da igualdade soberana. Vattel combinou elementos do jusnaturalismo e do positivismo, e minimizou a importância daquele ao dar ênfase às normas que resultavam da prática dos Estados. ${ }^{4}$

Do empirismo da Renascença derivou o positivismo, que veio a combinar-se com a doutrina da soberania e afirmar o poder do soberano. A partir desta atitude filosófica, o próximo passo foi “... reinterpretar o direito internacional não em termos de conceitos derivados da ra-

1 K. Holsti apud Mello, Celso D. de Albuquerque, Curso de Direito Internacional Público, 15 a. ed., Rio de Janeiro, Renovar, 2004, vol. I, p. 171.

2 Boson, Gerson de Britto Mello, Direito internacional público: o Estado em direito das gentes, Belo Horizonte, Del Rey, 2004.

3 Shaw, Malcolm N., International Law, 6a. ed., Cambridge, Cambridge University Press, 2008.

4 Vattel, Emer de, O Direito das Gentes, prefácio e tradução Vicente Marotta Rangel, Brasília, Editora Universidade de Brasília, 2004. 
zão, mas em termos do que efetivamente acontecia entre os estados competidores".

\section{A Consolidação do Estado-nação}

O contexto histórico do surgimento e fortalecimento do Estado-nação moderno marca a gênese do Direito Internacional: este surgiu com o objetivo primeiro de coordenar as relações entre os Estados, que, em meados do século XVI, eram os únicos sujeitos de Direito Internacional por excelência. ${ }^{6}$

A construção do Estado-nação como ente abstrato deu-se de forma desigual ao redor do mundo, tendo sua consolidação ocorrida primeiramente na Europa —-Portugal, Espanha, França e Inglaterra em especial, a partir do domínio do poder do Rei sobre os senhores feudais_-, para, em seguida, afirmar-se perante o poder dos Impérios e da Igreja do século XVII.

A partir do seu estabelecimento no Velho Continente, os movimentos colonialistas conduzidos pelas principais potências se encarregaram de propagar o Estado em nível internacional. A unificação do exército, da moeda, do Direito, da cultura e a criação de uma nacionalidade única em seu interior foram essenciais à afirmação do Estado como ente abstrato, separado das figuras dos governantes.

Projeto eminentemente liberal, o Estado moderno se origina, no entender de Boaventura de Sousa Santos, a partir de "uma simplificação brutal da vida... as pessoas têm família, têm cultura, falam uma língua, têm identidades, vivem em aldeias, nas vilas, nas cidades, e repentinamente se convertem em indivíduos, pois o que conta é ser indivíduo”. ${ }^{7}$ Ao indagar, diante da multiplicidade de culturas na Europa, o por que

5 Shaw, Malcolm N., International Law, cit., p. 25 (tradução nossa).

6 Rosenne, Shabtai, The Perplexities of Modern International Law: General Course on Public International Law. Recueil des Cours, t. 291, Leiden, Boston, Martinus Nijhoff Publishers, 2002; Creveld, Martin van, Ascensão e declínio do Estado, trad. Jussara Simões, São Paulo, Martins Fontes, 2004.

7 Santos, Boaventura de Sousa, Pensar el Estado e la sociedad: desafios actuales, Buenos Aires, Waldhuter Editores, 2009, p. 205 (tradução nossa). 
de apenas uma destas tornar-se a cultura do Estado, conclui criticamente o autor: “... somente uma, a que se considera mais desenvolvida, merece ser a cultura oficial. Todas as demais não contam; conta, unicamente, a cultura mais avançada”. ${ }^{8}$

A busca por uma uniformização de modos de vida é a essência do Estado:

Portanto, a tarefa de construção do Estado nacional (do Estado moderno) dependia da construção de uma identidade nacional ou, em outras palavras, da imposição de valores comuns que deveriam ser compartilhados pelos diversos grupos étnicos, pelos diversos grupos sociais para que assim todos reconhecessem o poder do Estado... A formação do Estado moderno está, portanto, intimamente relacionada com a intolerância religiosa, cultural, a negação da diversidade fora de determinados padrões e limites. ${ }^{9}$

Desde modo, com o vácuo de poder decorrente da erosão do poder papal e da inviabilidade do poder feudal para organizar as práticas econômicas, mercantis e políticas da Idade Moderna, uma nova forma de organização político-social vem à tona, com a força e o respaldo do pensamento europeu dominante: "O Estado moderno apresenta-se, pois, como um produto da cultura ocidental, erigido sobre um funcionalismo especializado e um direito racional". ${ }^{10}$

O Estado nacional moderno somente foi possível com o desenvolvimento do conceito da soberania estatal ${ }^{11}$, noção esta que se desdobra nos níveis interno e externo. Em nível interno, a soberania estatal representa a instituição de uma ordem jurídica chefiada pelo Estado, que,

8 Ibidem, pP. 206-207 (tradução nossa).

9 Magalhães, José Luiz Quadros de, "Identidades e identificações: da possibilidade de construção de uma ética universal”, Veredas do Direito, vol. 5, no. 9/10, jan./dez. 2008, p. 47.

10 Soares, Mário Lúcio Quintão, Teoria do Estado: Novos Paradigmas em face da Globalização, 3a. ed., São Paulo, Atlas, 2008, p. 74.

${ }^{11}$ Este conceito se desenvolve a partir da ideia de communitas orbis (comunidade mundial) vislumbrada pelo internacionalista Francisco de Vitoria (séc. XVI), para em um momento posterior vir a se consolidar nas obras de Hugo Grotius, Jean Bodin, Thomas Hobbes e John Locke. Nesse sentido, ver: Ferrajoli, Luigi, A soberania no mundo moderno: nascimento e crise do Estado nacional, trad. Carlo Coccioli e Márcio Lauria, São Paulo, Martins Fontes, 2007. 
por sua vez, detém o monopólio do uso da força. Em nível externo, implica a existência de um estado de natureza.

Hoje, quando os Estados não europeus representam a grande maioria da sociedade internacional — sendo também maioria em participação nas Nações Unidas - , as referências às bases europeias persistem, conduzindo à seguinte reflexão: “... se a sociedade internacional contemporânea tem uma base cultural, não é a de uma cultura genuinamente global, mas sim a cultura da chamada 'modernidade'... a cultura das potências europeias dominantes". ${ }^{12}$

O ideário liberal wilsoniano — pelo qual as fronteiras do Estado deviam coincidir com as fronteiras das nacionalidades e das línguasanota Eric J. Hobsbawm, não condiz com as realidades de muitos conjuntos de populações — minorias, nações — vivendo na Europa, Américas e na África. A criação bem definida de Estados territoriais coerentes, respectivos à determinada nacionalidade e traço cultural específico, implicou a expulsão ou o extermínio em massa das minorias e um embate constante entre povos confinados nos mesmos marcos territoriais. ${ }^{13}$

Afirma Jacques Sémelin que muitas das grandes tragédias humanitárias do século XX resultam da dinâmica social uniformizadora e intolerante do Estado moderno. ${ }^{14} \mathrm{O}$ processo de "importação" do Estadonação — para não citar as Américas do Sul e Central e a Ásia- jamais logrou o êxito conquistado, por exemplo, na Europa Ocidental e na América do Norte. ${ }^{15}$

\section{1492: AS ORIGENS DO DIREITO INTERNACIONAL MODERNO}

Inicialmente, o ano de 1492 é emblemático sob dois aspectos centrais: a Europa assume a posição central no mundo com a expansão ultrama-

12 Bull, Hedley, A Sociedade Anárquica: um estudo da ordem na política mundial, trad. Sérgio Bath, Brasília, Editora Universidade de Brasília, 2002, p. 49.

13 Hobsbawm, Eric J., Nações e Nacionalismo desde 1780: programa, mito e realidade, 5a. ed., trad. Maria Celia Paoli e Anna Maria Quirino, Rio de Janeiro, Paz e Terra, 1990.

14 Sémelin, Jacques, Purificar e destruir: usos políticos dos massacres e dos genocídios, trad. Jorge Bastos, Rio de Janeiro, DIFEL, 2009.

15 Creveld, Martin van, Ascensão e declínio do Estado, cit. 
rina, ao mesmo tempo em que expulsa os mouros, ciganos e judeus da península ibérica, forjando de modo definitivo a identidade européia.

O tipo de relação internacional que se desenvolve a partir deste marco temporal decorre, dentre outros fatores, da desconsideração e intolerância para com o novo, ao situar o pensamento europeu como a única concepção epistemológica válida e fundamento para a modernidade. ${ }^{16}$ Tal tese, defendida, dentre outros, por Enrique Dusse ${ }^{17}$ e Tzvetan Todorov, ${ }^{18}$ posiciona o Direito Internacional como uma consequência do colonialismo e do imperialismo, abrindo interessantes e válidas possibilidades de releitura da doutrina clássica.

Por detrás do conceito de modernidade — cujos expoentes mais notórios são a razão moderna, o método científico e o empirismo, derivados das ciências naturais e aperfeiçoados por Descartes ${ }^{19}$ - , subjaz o mito da modernidade, assim definido por Dussel:

\begin{abstract}
Por um lado, [o mito da modernidade] se autodefine a própria cultura como superior, mais "desenvolvida"...; por outro lado, a outra cultura é determinada como inferior, rude, bárbara, sempre sujeito de uma "imaturidade" culpável. De maneira que a dominação (guerra, violência) que é exercida sobre o Outro é, na realidade, emancipação, "utilidade”, "bem” do bárbaro que se civiliza, que se desenvolve ou "moderniza". ${ }^{20}$
\end{abstract}

A Europa, ao assumir centralidade ${ }^{21}$ nas relações internacionais ao final do século XV, constitui sua própria identidade. O contato com o

16 Santos, Boaventura de Sousa, "Para além do pensamento abissal: das linhas globais a uma ecologia de saberes”, in Santos, Boaventura de Sousa y Meneses, Maria Paula (orgs), Epistemologias do Sul, São Paulo, Cortez Editora, 2010, p. 31 - 83.

17 Dussel, Enrique, 1492: o encobrimento do outro: a origem do mito da modernidade, trad. Jaime A. Clasen, Petrópolis, Editora Vozes, 1993.

18 Todorov, Tzvetan, A Conquista da América: a questão do outro, trad. Beatriz Perrone-Moisés, São Paulo, Martins Fontes, 2003.

19 Santos, Boaventura de Souza, Um discurso sobre as ciências, 7a. ed., São Paulo, Cortez Editora, 2010.

20 Dussel, Enrique, 1492: o encobrimento do outro: a origem do mito da modernidade, cit., p. 75.

21 Até o final do século XV, a Europa era considerada periferia do mundo turco muçulmano, que se estendia desde o norte da África, passando pela Mesopotâmia e chegando às atuais Filipinas. Conferir: Dussel, Enrique, “Europa, modernidade e eurocentrismo”, in Lander, Ed- 
Novo Mundo, iniciado por Cristóvão Colombo, é ditado por uma por postura de superioridade do europeu em relação aos índios, às suas culturas e modos de vida.

Responsável pelos primeiros passos da “... constituição da experiência existencial de uma Europa ocidental, atlântica, 'centro' da história”22, Colombo age como autêntico hermeneuta finalista, antecipando a relação de encobrimento prestes a informar o colonialismo: por meio do argumento de autoridade, o explorador "sabe de antemão o que vai encontrar; a experiência concreta está aí para ilustrar uma experiência que se possui". ${ }^{23}$ É esta completa desconsideração do outro - Com uma conotação sacrificial, na medida em que é sobre a negação da sua condição humana que se erige o pensamento dominante - a característica elementar da modernidade, que se alicerça sobre o mito da violência.

$\mathrm{O}$ universalismo que se desenhava no século $\mathrm{XV}$, recheado de justificativas exaltantes da superioridade moral e científica europeia, teve sua genética de violência denunciada pelo padre espanhol Bartolomé de Las Casas. Convencido das injustiças advindas da exploração do Novo Mundo, em especial o sistema de encomiendas, Las Casas se opôs ao modelo colonial, travando amplos debates com representantes da Igreja, da Corte e opositores acadêmicos. Dentre estes últimos, destacou-se Juan Ginés de Sepúlveda, defensor do direito de intervenção e dominação europeu sobre as Américas. O embate entre Sepúlveda e Las Casas acerca do direito de ingerência do governo espanhol nas Américas ganhou notoriedade a partir de 1550 .

Os argumentos de Sepúlveda são resumidos por Immanuel Wallerstein, que destaca a contemporaneidade deste debate para o sistema internacional:

... esses são os quatro argumentos básicos que têm sido utilizados para justificar todas as "intervenções" subseqüentes dos "civilizados" do mundo moderno em zonas "não-civilizadas": a barbárie dos outros, o fim das práticas que violam os

gardo (org.), A colonialidade do saber: eurocentrismo e ciências sociais. Perspectivas latino-americanas, Buenos Aires, CLACSO, 2005.

22 Dussel, Enrique, 1492: o encobrimento do outro: a origem do mito da modernidade, cit., p. 32.

23 Todorov, Tzvetan, A Conquista da América: a questão do outro, cit. p. 23. 
valores universais, a defesa de inocentes em meio aos cruéis e a possibilidade de disseminar valores universais. ${ }^{24}$

A despeito dos reconhecidos esforços de Las Casas, a tese de Sepúlveda terminou por prevalecer, fornecendo a fundamentação para a conquista e exploração. A missão civilizatória europeia se propagou pelo mundo e, segundo Wallerstein, assumiu novas roupagens, em grande medida institucionalizadas pelas normas internacionais: a defesa dos Direitos Humanos - e os debates em torno do multiculturalismo, universalismo, direito de ingerência e Estados Fracassados - , a pretensa superioridade da civilização ocidental (diante do choque de civilizações ${ }^{25}$ ) e a verdade científica do mercado — postulados da eficiência e naturalização das estruturas mercadológicas, em nível nacional e internacional. ${ }^{26}$

A centralidade geográfica mundial europeia foi acompanhada da assunção do pensamento e valores ocidentais, e a conseqüente desqualificação de modos de pensar e conceber o mundo que não se enquadrassem nos moldes racionais-empiristas. Um abismo se forma entre o conhecimento que é admitido e o tipo de pensamento primitivo, arcaico, de comunidades e povos coloniais. Assim, a ciência moderna detém o monopólio da distinção entre o que é falso e o que é verdadeiro, o que é científico em oposição ao não-científico.

Nos domínios do direito, e em especial do Direito Internacional, o conhecimento válido “... é determinado por aquilo que conta como legal ou ilegal de acordo com o direito oficial do Estado ou com o direito internacional". ${ }^{27}$ As realidades que não se enquadrem nos requisitos estabelecidos são eliminados, compondo o outro lado da linha do conhe-

24 Wallerstein, Immanuel, O Universalismo Europeu: a retórica do poder, trad. Beatriz Medina, São Paulo, Boitempo, 2007, p. 35. Para uma discussão acerca do contexto histórico do debate, conferir as páginas 29-40.

25 É esta a tese de Samuel Huntington ao defender que o próximo padrão de conflitos internacionais dar-se-á entre civilizações, em virtude das linhas falhas (e inconciliáveis) existentes entre elas. Conferir: Huntington, Samuel, The Clash of Cilvilizations and the Remaking of World Order, New York, Simon \& Schuster, 2003.

26 Wallerstein, Immanuel, O Universalismo Europeu: a retórica do poder, cit.

27 Santos, Boaventura de Sousa, "Para além do pensamento abissal: das linhas globais a uma ecologia de saberes”, cit., p. 34. 
cimento que, conforme Boaventura de Sousa Santos, "compreende uma vasta gama de experiências desperdiçadas, tornadas invisíveis, tal como os seus autores, e sem uma localização territorial fixa”. ${ }^{28}$

Importantes trabalhos têm dedicado atenção à influência do imperialismo e colonialismo à formação do Direito das Gentes. Dentre estes, merece destaque o estudo de Anthony Anghie. Partindo da doutrina de Francisco de Vitoria, o autor visita as relações comercias do século XVII, o sistema de Mandatos da Liga das Nações, as instituições financeiras internacionais e a guerra ao terror, lançando reflexões acerca do papel desempenhado pelo colonialismo, a teoria da soberania e o imperialismo — inglês e norte-americano em especial — na constituição do Direito Internacional moderno. ${ }^{29}$

Das relações imperialistas coloniais, o contato com o outro, imediatamente encoberto e carente de padrões civilizatórios pré-constituídos, retira o Direito Internacional sua vocação moderna.

\section{O ESTADO PLURINACIONAL BOLIVIANO E EQUATORIANO}

O processo histórico-social que culminou na nova Constituição boliviana de 2008 guarda suas origens na própria formação do Estado boliviano. A diversidade de povos e culturas neste país — são 36 povos originários atualmente - foi, desde o período colonial até a segunda metade do século $\mathrm{XX}$, reprimida e situada às margens dos poderes públicos e oligarquias constituídas.

Confirmando a regra supramencionada do modo de consolidação do Estado-nação ao redor do globo, na Bolívia o Estado se assentou sobre a exclusão e uniformização de modos de vida, economia, propriedade e representação política de povos que não se enquadravam no modelo estabelecido. Conforme esclarece Luis Tapia,

28 Ibidem, p. 34.

29 Anghie, Anthony, Imperialism, Sovereignty and the Making of International Law, Cambridge, Cambridge University Press, 2004. 
[existe] uma crise de correspondência entre o estado boliviano, a configuração de seus poderes, o conteúdo de suas políticas, por um lado, e, por outro, o tipo de diversidade cultural entendida de maneira autorganizada... dos povos indígenas. ${ }^{30}$

Esta crise de correspondência se desdobra nos paradoxos de uma sociedade multicultural: (i) a oposição entre a diversidade da população e o governo oriundo de um modelo único e (ii) as múltiplas matrizes culturais, em contraste com a rigidez e uniformização das instituições públicas estatais. Deste modo, o desafio do Estado Plurinacional boliviano consiste em harmonizar a diversidade cultural em um contexto de organização estatal instituído - existem povos originários, como o quéchua, que desconhecem a forma estatal de organização social.

$\mathrm{Na}$ multicultural sociedade boliviana, os povos originários foram finalmente incorporados no plano político a partir da constituição de 2008. Dos 411 artigos que compõem a Carta Fundamental boliviana, 80 são destinados à questão indígena. A equivalência da justiça indígena à justiça institucionalizada; a garantia de representação dos povos originários no parlamento; a reorganização territorial do país, o que garante autonomia às frações territoriais (departamental, regional, municipal e indígena), cada uma delas podendo organizar suas eleições e administrar os recursos econômicos; e o reconhecimento dos direitos de família e propriedade de cada povo originário, são alguns dos pontos essenciais do novo projeto constitucional. ${ }^{31}$

Desde sua independência política em 1830, o Equador foi regido por 18 constituições nacionais. Os textos constitucionais do século XIX espelharam as dinâmicas sociais de um país dominado por elites e oligarquias, com forte influência destas na vida política e econômica, em detrimento da participação dos povos e comunidades originárias. A centralização do Estado, dirigido por um executivo forte, foi um denominador comum do período. A questão econômica não era tratada devidamente, prevalecendo o embate entre conservadores e liberais pelo controle da máquina pública.

\footnotetext{
30 Tapia, Luis, "Una reflexión sobre la idea de Estado plurinacional”, OSAL, Buenos Aires, CLACSO, ano VIII, no. 22, 2007, p. 48 (tradução nossa).

31 Magalhães, José Luiz Quadros de y Weil, Henrique, "Bioética no Estado de Direito Plurinacional”, Revista Direitos Culturais, vol. 5, no. 8, 2010, p. 13-26.
} 
O reconhecimento dos direitos individuais é notado nas primeiras Cartas do século XX. Já no começo deste período trabalhadores, camponeses e povos originários compuseram forte oposição às práticas oligárquicas. A busca por maior participação na vida política motivou estes grupos a disputarem eleições, ocupando cargos públicos e lutando por reformas sociais, econômicas e políticas.

Em retrospectiva, a nova Constituição de 2008 buscou “... afirmar os direitos laborais e sociais; fixar o papel econômico do Estado; e promover a responsabilidade social da propriedade privada”. ${ }^{32}$ De grande significância para o projeto plurinacional, o texto constitucional reconheceu e incorporou no seio político as culturas e comunidades historicamente excluídas, conforme se depreende da leitura dos artigos 10 e 11: "Os povos e as pessoas indígenas têm direito a pertencer a uma comunidade ou nação indígena, de conformidade com as tradições e costumes da comunidade ou nação que se trate. Não pode haver nenhuma discriminação... ao exercício deste direito". ${ }^{33}$

A nova Constituição do Equador também instituiu as bases para a consolidação de uma sociedade multicultural neste país. A incorporação dos povos indígenas e comunidades originárias ao projeto constitucional representa, no entender de Agustín Grijalva, uma completa reformulação das tradicionais categoriais legais e hermenêuticas. Tanto a ênfase quanto o diferencial desta nova formulação estatal repousam na instituição de um sistema de foros de deliberação democrático e multicultural:

O constitucionalismo plurinacional deve ser um novo tipo de constitucionalismo baseado em relações interculturais igualitárias, que redefinam e reinterpretem os direitos constitucionais e reestruturem a institucionalidade proveniente do Estado Nacional. O Estado plurinacional não é e não deve ser reduzido a uma Constituição que inclua um reconhecimento puramente culturalista, à vezes somente formal, por parte de um Estado em realidade instrumentalizado para o domínio

32 Paz, Juan J. y Pazmiño, Miño Capeda Diego, "El proceso constituyente desde una perspectiva histórica”, in La Tendencia: Análisis Nueva Constitución, Ecuador, Instituto Latinoamericano de Investigaciones Sociales, 2008, p. 39 (tradução nossa).

33 Grijalva, Agustín, "El Estado Plurinacional e Intercultural en la Constitución Ecuatoriana del 2008”, cit., p. 56 (tradução nossa). 
de povos de culturas distintas, senão um sistema de foros de liberação intercultural autenticamente democrático. ${ }^{34}$

A institucionalização de um constitucionalismo plurinacional demanda um engajamento profundamente intercultural. Tal constitucionalismo, para ser apto a romper com as bases uniformizadoras do Estado-nação (em suas várias vertentes), deve ser dialógico, uma vez que demanda uma abertura comunicativa e deliberativa permanente para alcançar o melhor entendimento com o outro, o diferente. Deve ser concretizante, pois se compromete com a busca de soluções específicas e ao mesmo tempo consistentes para situações individuais e complexas; tal fato requer do intérprete constitucional uma abordagem interdisciplinar e intercultural. E, por fim, o constitucionalismo em sua vertente plurinacional não dispensa uma postura garantista, porque trabalha diretamente para a construção de sentidos e significados para o rol de direitos fundamentais. Na reflexão de Grijalva, “... o direito à identidade e diferença cultural deve inscrever-se em um marco de direitos humanos conforme vão sendo definidos pelo Estado plurinacional”. ${ }^{35}$

Em oposição ao constitucionalismo moderno, no qual os conceitos de povo e soberania popular contribuíram para a uniformização cultural por meio da sobreposição da cultura dominante — dita civilizada - por sobre as demais formas de organização familiar, econômica e política ${ }^{36}$, o constitucionalismo plurinacional deve se desenvolver atendendo as peculiaridades dos processos histórico-sociais de cada Estado — não existe um modelo de Estado Plurinacional, e sim modelos de Estados Plurinacionais; deve superar a dicotomia tradicional/contemporâneo, galgando uma equivalência entre "o que é simultâneo e o que é contemporâneo: cada um à sua maneira, porém contemporâneos ao final”. ${ }^{37}$ Portanto:

34 Grijalva, Agustín, "El Estado Plurinacional e Intercultural en la Constitución Ecuatoriana del 2008”, in Revista Ecuador Debate, no. 75, 2008, pp. 50 e 51 (tradução nossa, destaque nosso).

35 Ibidem, p. 53 (tradução nossa).

36 Santos, Boaventura de Sousa, Pensar el Estado e la sociedad: desafios actuales, Buenos Aires, Waldhuter Editores, 2009.

37 Ibidem, p. 209 (tradução nossa). 
A ideia de Estado Plurinacional pode superar as bases uniformizadoras e intolerantes do Estado nacional, onde todos os grupos sociais devem se conformar aos valores determinados na constituição nacional em termos de direito de família, direito de propriedade e sistema econômico, entre outros aspectos importantes da vida social... A grande revolução do Estado Plurinacional é o fato de que este Estado constitucional, democrático participativo e dialógico, pode finalmente romper com as bases teóricas e sociais do Estado nacional constitucional e democrático representativo (pouco democrático e nada representativo dos grupos não uniformizados), uniformizador de valores e, logo, radicalmente excludente. ${ }^{38}$

À medida que o Estado Plurinacional se desenvolve, novas formas de lidar com diferenças culturais emergem. Para além do embate entre universalistas e relativistas, a plurinacionalidade é fundada na certeza da incompletude de cada cultura, iluminando um diálogo aberto e inclusivo, pautado pelo mútuo reconhecimento, em oposição ao encobrimento.

A manutenção de espaços permanentes de construção de consensos deve constituir-se em prática constante, sob o risco de desintegrar o engajamento e mobilização social e a participação no espaço político. ${ }^{39} \mathrm{~A}$ hermenêutica diatópica, proposta por autores como Raimundo Panikkar ${ }^{40}$, pode melhor expressar o viés intercultural que o Estado Plurinacional envolve: o ato de compreender cada cultura como uma - mas única, no sentido de que não pode ser repetida - dentre tantas outras implica, necessariamente, no reconhecimento de seu valor inerente.

Por se tratar de acontecimento extremamente recente, seus desdobramentos para a prática constitucional e internacionalista ainda encontram-se em fase embrionária. No entanto, este novo paradigma já se mostra apto a tratar de questões importantes, como os temas de bioética, ${ }^{41}$ em geral abordados sob uma perspectiva parcial e intolerante.

38 Magalhães, José Luiz Quadros de y Weil, Henrique, "Bioética no Estado de Direito Plurinacional", cit., pp. 17 e 18.

39 Žižek, Slavoj, En defensa de la intolerância, Madrid, Ediciones Sequitur, 2008.

40 Panikkar, Raimundo, "Seria a noção de direitos humanos uma concepção universal?", in Baldi, César Augusto, Direitos Humanos na Sociedade Cosmopolita, Rio de Janeiro, Renovar, 2004, pp. 205-238.

${ }^{41}$ Magalhães, José Luiz Quadros de y Weil, Henrique, "Bioética no Estado de Direito Plurinacional”, cit. 
A reflexão que se propôs até então foi pensar em alternativas de governo multicultural, porém com um viés igualitário, e não unificador. Tais propostas poderão ter bases materiais diversas do capitalismo, sendo aptas, finalmente, a alcançar uma correspondência mais perfeita entre a forma de governo e a diversidade cultural do país. Contudo, alerta Luis Tapia, um desafio deve ser enfrentado: "essas alternativas não existem, todavia; devem ser imaginadas e construídas como parte de uma vida política compartida em condições de igualdade". ${ }^{42}$

\section{CONSIDERAÇÕES FINAIS}

Os cinco séculos de história do Estado-nação moderno, quando analisados de fora do eixo Europa-América do Norte, são marcados por um genética de violência e intolerância, cujos traços iniciais foram identificados, simbolicamente, no ano 1492. Marco da identidade ocidental e do Direito Internacional moderno, os desdobramentos da exploração colonial são identificados nos padrões de relação diante do novo, do diferente: a missão civilizadora, o universalismo de valores e instituições e, finalmente, o abismo epistemológico que separa o conhecimento científico dos saberes ditos bárbaros e arcaicos.

Os povos alocados na periferia das relações jurídicas internacionais passam, em nossos tempos, por processos de exclusão e violência que guardam estreita relação com o paradigma da modernidade identificado acima. A compreensão da evolução do Direito das Gentes a partir de tais referenciais torna-se, destarte, essencial, perpassando as propostas clássicas para culminar nas alternativas de pesquisa que analisam as premissas fundadoras da disciplina, para a posterior proposição de alternativas. Temas como desenvolvimento, pobreza, segurança, Direitos Humanos e intervenção para fins humanitários são passíveis de maior reflexão tomando-se, como ponto de partida, os alicerces dialógicos e plurais do Estado Plurinacional.

42 Tapia, Luis, "Una reflexión sobre la idea de Estado plurinacional”, cit., p. 63 (tradução nossa). 
A proposta plurinacional se insere em um panorama de superação de dicotomias excludentes, que originaram o mito da missão civilizatória das nações desenvolvidas. Enquanto instrumento civilizador, o Direito Internacional remonta ao ano de 1492, e seus fundadores - em particular Francisco Vitoria - já se depararam com os desafios advindos de sua condição moderna. Enquanto instrumento emancipador, o Direito Internacional requer uma ampliação de seu espectro epistemológico, de modo a contemplar as experiências de povos, comunidades e coletividades. Trata-se de uma atitude dialógica, aberta e plural, em contraste à sua faceta unificadora, estigmatizante e violenta.

\section{BIBLIOGRAFIA}

ANGHIE, Anthony, Imperialism, Sovereignty and the Making of International Law, Cambridge, Cambridge University Press, 2004.

Boson, Gerson de Britto Mello, Direito internacional público: o Estado em direito das gentes, Belo Horizonte, Del Rey, 1994.

Bull, Hedley, A Sociedade Anárquica: um estudo da ordem na política mundial, trad. Sérgio Bath, Brasília, Editora Universidade de Brasília, 2002.

CREveld, Martin van, Ascensão e declínio do Estado, trad. Jussara Simões, São Paulo, Martins Fontes, 2004.

DuSSEL, Enrique, "Europa, modernidade e eurocentrismo", in LANDER, Edgardo (org.), A colonialidade do saber: eurocentrismo e ciências sociais. Perspectivas latino-americanas, Colección Sur Sur, Buenos Aires, CLACSO, 2005.

, 1492: o encobrimento do outro: a origem do mito da modernidade, trad. Jaime A. Clasen, Petrópolis, Editora Vozes, 1993.

FERRAJOLI, Luigi, A soberania no mundo moderno: nascimento e crise do Estado nacional, trad. Carlo Coccioli e Márcio Lauria, São Paulo, Martins Fontes, 2007.

Grijalva, Agustín, "El Estado Plurinacional e Intercultural en la Constitución Ecuatoriana del 2008”, Revista Ecuador Debate, núm. 75, p. 49-62, 2008. 
Hobsbawm, Eric J., Nações e Nacionalismo desde 1780: programa, mito e realidade, 5a. ed., trad. Maria Celia Paoli e Anna Maria Quirino, Rio de Janeiro, Paz e Terra, 1990.

Huntington, Samuel, The Clash of Civilizations and the Remaking of World Order, New York, Simon \& Schuster, 2003.

MagalHÃes, José Luiz Quadros de y Weil, Henrique, "Bioética no Estado de Direito Plurinacional”, Revista Direitos Culturais, vol. 5, no. 8, 2010.

Magalhães, José Luiz Quadros de, "Identidades e identificações: da possibilidade de construção de uma ética universal”, in Veredas do Direito, vol. 5, no. 9/10, p. 45-61, jan./dez. 2008.

Mello, Celso D. de Albuquerque, Curso de Direito Internacional Público, 15a. ed., vols. I e II, Rio de Janeiro, Renovar, 2004.

PAZ, Juan J. e Pazmiño, Miño Capeda Diego, "El proceso constituyente desde una perspectiva histórica”, La tendencia: análisis nueva Constitución, Ecuador, Instituto Latinoamericano de Investigaciones Sociales, 2008, p. 26-45.

Rosenne, Shabtai, The Perplexities of Modern International Law: General Course on Public International Law, Recueil des Cours, t. 291, Leiden/ Boston, Martinus Nijhoff Publishers, 2002.

SAnTOS, Boaventura de Sousa, Um discurso sobre as ciências, 7a. ed., São Paulo, Cortez Editora, 2010.

, "Para além do pensamento abissal: das linhas globais a uma ecologia de saberes”, in Santos, Boaventura de Sousa y Meneses, Maria Paula (orgs). Epistemologias do Sul, São Paulo, Cortez Editora, 2010.

, Pensar el Estado e la sociedad: desafios actuales, Buenos Aires, Waldhuter Editores, 2009.

SÉmelin, Jacques, Purificar e destruir: usos políticos dos massacres e dos genocídios, trad. Jorge Bastos, Rio de Janeiro, DIFEL, 2009.

SHAW, Malcolm N., International Law, 6a. ed. Cambridge, Cambridge University Press, 2008.

SOARES, Mário Lúcio Quintão, Teoria do Estado: novos paradigmas em face da globalização, 3a. ed., São Paulo, Atlas, 2008.

TAPIA, Luis, "Una reflexión sobre la idea de Estado plurinacional", OSAL, Buenos Aires, CLACSO, ano VIII, no. 22, 2007. 
Todorov, Tzvetan, A Conquista da América: a questão do outro, trad. Beatriz Perrone-Moisés, São Paulo, Martins Fontes, 2003.

VAtTel, Emer de, O Direito das Gentes, prefácio e tradução Vicente Marotta Rangel, Brasília, Editora Universidade de Brasília, 2004.

Wallerstein, Immanuel, O universalismo europeu: a retórica do poder, trad. Beatriz Medina, São Paulo, Boitempo, 2007.

ŽIŽEK, Slavoj, En defensa de la intolerância, Madrid, Ediciones Sequitur, 2008. 